\title{
Early Outcome After Limb Salvage Surgery of a Rare Case of Gollop-Wolfgang Complex in a Limited Resource Setting in Africa
}

\author{
Nana C Theophile ${ }^{1 *}$, Batchom A Daudet ${ }^{2}$, Bombah M Freddy ${ }^{2}$, Arung J Etaya ${ }^{1}$, Ebai N Hensure ${ }^{1}$ and Palle J Ngunde ${ }^{1}$ \\ ${ }^{1}$ Department of Surgery and Specialties, Faculty of Health Sciences University of Buea, Cameroon \\ ${ }^{2}$ Department of Surgery, Faculty of Medicine and Pharmaceutical Sciences, University of Douala, Cameroon
}

Submission: July 23, 2021; Published: August 02, 2021

*Corresponding author: Dr. Nana Chunteng Theophile, Department of Surgery and Specialties, Faculty of Health Sciences University of Buea, Cameroon

\section{Abstract}

Introduction: Gollop-Wolfgang Complex (GWC) is a rare congenital musculoskeletal disorder, characterized by a distal femoral duplication and tibial agenesis associated or not with hand ectrodactyly. Few cases of GWC have been reported in sub-Saharan Africa and most of them were treated by amputation and prosthetic replacement. Amputation is not sometimes accepted by parents for many reasons; therefore, alternatives to amputation should be considered. This is a rare case of GWC treated without amputation in a limited resource setting.

Case presentation: This is the case of a 6-year-old boy who consulted at the outpatient orthopaedic clinic with clinical and radiological aspects consistent with a Gollop-Wolfgang complex. His parents refused amputation and opted for alternative treatment. Limb salvage surgery although difficult in our setting was done. The boy could mobilise using crutches despite some residual bilateral cavovarus feet deformities.

Conclusion: Limb salvage surgery of GWC is a difficult treatment option in limited resource settings. It could be a good alternative to amputation especially in the absence of parental consent to amputation.

Keywords: Gollop-Wolfgang complex; Limb salvage

\section{Introduction}

Gollop-Wolfgang Complex (GWC) is a rare congenital musculoskeletal anomaly characterized by a distal femoral duplication and tibial agenesis associated or not with hand ectrodactyly [1,2]. It is often associated with congenital anomalies of heart, gastrointestinal and genitourinary systems [3]. This condition was initially described by Gollop et al in 1980 in two brothers with ectrodactyly and unilateral bifurcation of the femur, absence of both tibiae and monodactyly of the feet [4]. In 1984, Wolfgang reported a case of unilateral femoral bifurcation and absence of the tibia [5]. The eponym «Gollop-Wolfgang complex» was introduced in 1986 by Lurie \& Ilyina [6]. Several associations between GWC and maternal use of antiepileptic drugs, most notably that of sodium valproate and cabamazepines, have been documented previously $[7,8]$. The best treatment option for patients with GWC is early knee disarticulation and resection of the protruded bifurcated femur followed by fitting of a modern prosthesis [9-11].

Few cases of GWC have been reported in sub Saharan Africa and most of them were treated by amputation and prosthetic replacement $[9,11,12]$. Amputation is not sometimes accepted by parents for many reasons; therefore, alternatives to amputation should be considered [13]. We hereby report a case of GWC in a Cameroonian male child whose parents refused amputation and opted for limbs salvage option, a choice which is difficult to carryout in a poor resource setting.

\section{Case Report}

This is the case of a 6-year-old boy who presented to our clinic with deformities of both lower limbs evolving from birth. He is 3rd child and has 5 siblings who don't have any musculoskeletal malformations. He was born at term through normal per-vaginal delivery. There was no family history of any congenital deformity. His parents are healthy, non-consanguineous, and didn't report any significant past medical history. The mother didn't report any pathology during pregnancy. She doesn't consume any teratogenic drugs nor alcohol and doesn't smoke. There was no history of exposure to radiation before or during pregnancy.

Generally, the boy looked very active, well oriented in person, place and time, and had a normal level of intelligence compared to his peers. Examination of the right lower limb revealed a distal 


\section{Orthopedics and Rheumatology Open Access Journal (OROAJ)}

thigh which was widened with a triangular appearance in the form of a Y. Palpation revealed a distal femoral bifurcation. There was a flexion deformity of the right knee of about 100 degrees, the patella was not palpable, and he couldn't maintain knee extension.
The right leg appeared shortened with absence of the tibia. There was cavovarus foot deformity with hypoplasia of the first ray of the foot (Figure 1).

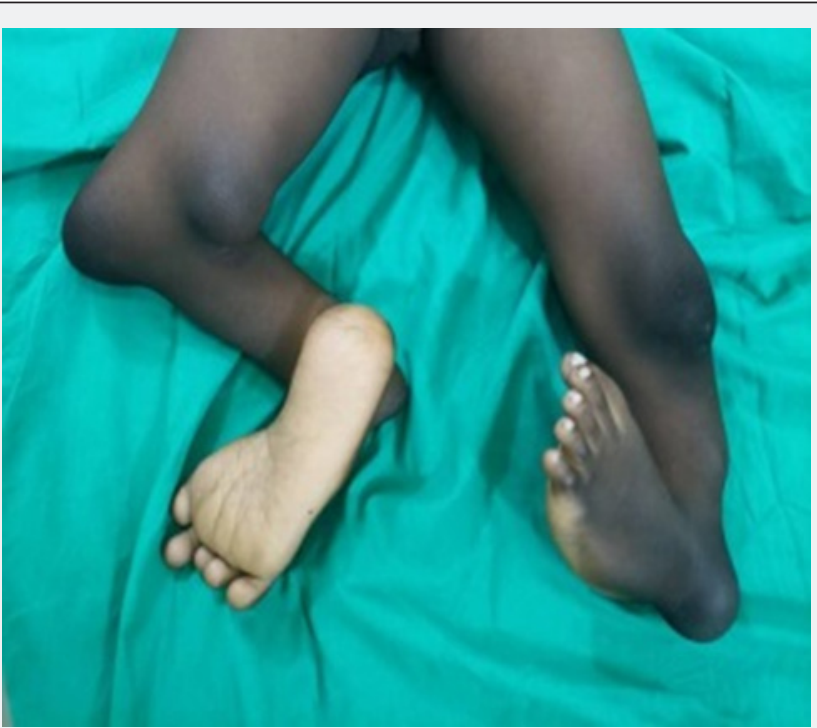

Figure 1: Clinical picture showing a widened distal right thigh with a bifid distal femur (white arrow), a hypoplastic first ray of the right foot, flexion deformity of the right knee, bilateral cavovarus feet deformities, and shortened legs.

He had good capillary filling and sensations were intact. Passive and active hip movements were normal. The hip and thigh of the left lower limb looked well, and there was active knee extension with full range of motion. The left leg was shortened, and the foot had a cavovarus deformity with normal toes (Figure 1). Radiographic films (Figure 2) showed a bifurcated right distal femur with bilateral tibia hemimelia (type Ia and type II for the right and left respectively according to JONES classification).

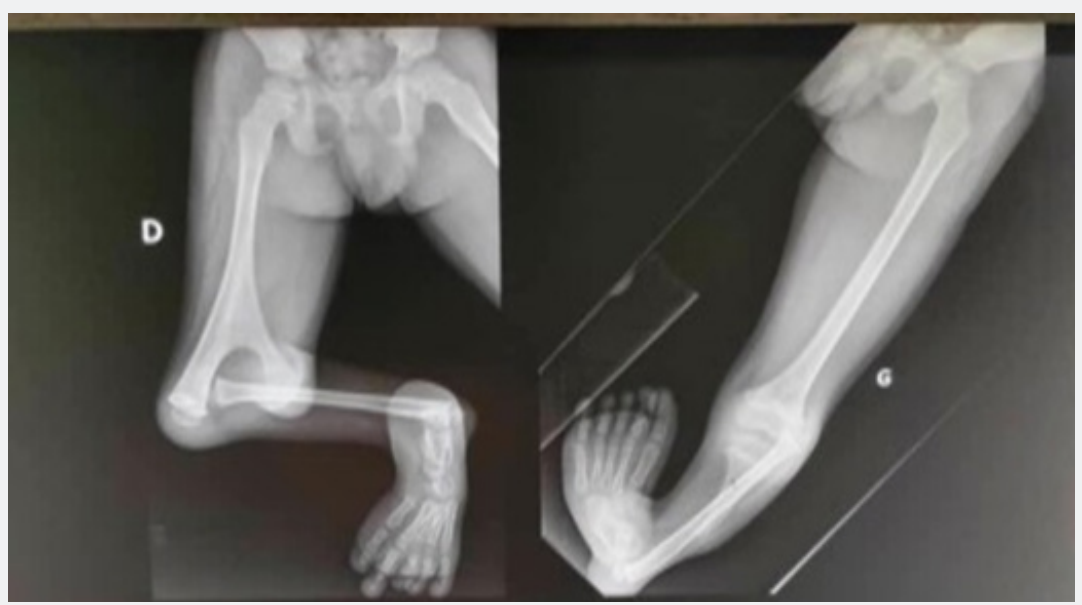

Figure 2: Radiological pictures showing a bifurcated right distal femur with bilateral tibia hemimelia (type la and type II for the right and left respectively according to JONES classification).

The above findings were consistent with a Gollop-Wolfgang deformity. On further examination, there were no upper limbs, cardiac, neurologic or renal deformities. For the right lower limb, the terminal portion of the medial branch of the bifurcated femur which was easily felt under the skin was excised. A Z-plasty was done on the skin posterior to the knee. Posterior knee soft tissue release permitted us to obtain complete knee extension. The talus was positioned under the distal fibular epiphysis and an external fixator was placed spanning the knee and ankle joints. For the left lower limb, medial soft tissue release of the foot was done, the reduction obtained was stabilized with an external fixator. A cast based back-slab was placed on both lower limbs to augment stabilization for six-week (Figure 3).

At six weeks' follow-up, there were some residual feet cavus, the external fixators were removed and replaced with circular 


\section{Orthopedics and Rheumatology Open Access Journal (OROAJ)}

casts which were maintained for further 6 weeks. After removal of the casts, two Knee-ankle-foot orthoses (KAFO) were fabricated and fitted in both lower limbs. Physiotherapy was commenced with re-education to walk using a pair of crutches. At twenty weeks (which was the latest visit), the boy could ambulate easily with the aid of his crutches (Figure 4) despite the residual cavus feet (Figure 4) but couldn't easily mobilize his right knee and couldn't also actively maintain knee extension. The parents were counseled on the need to change the KAFO as the child grows.

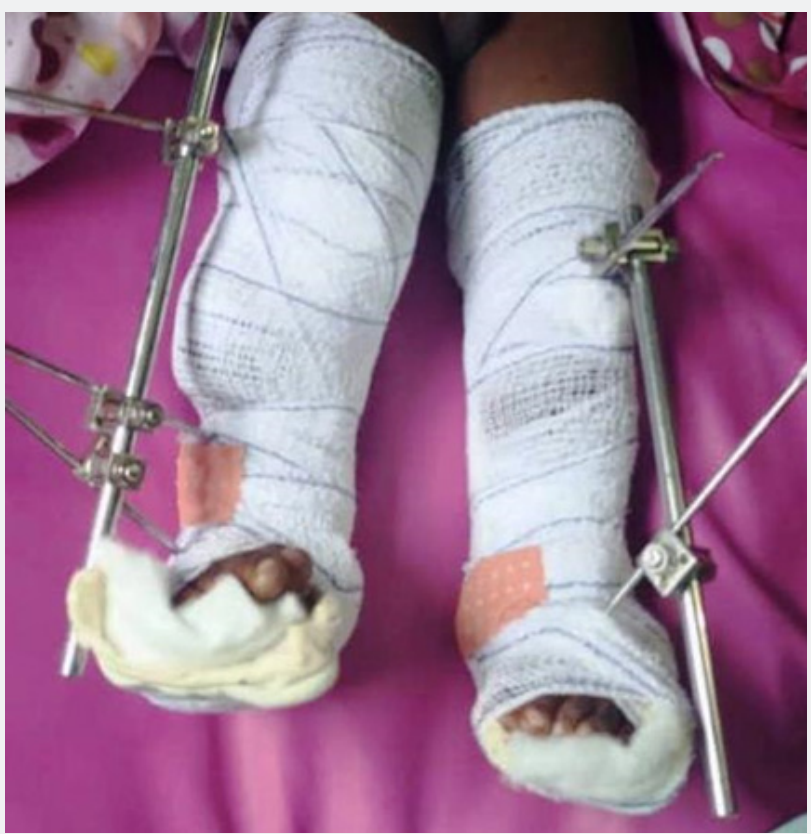

Figure 3: Immediate post-operative image showing a completely extended right knee, residual bilateral cavovarus feet.

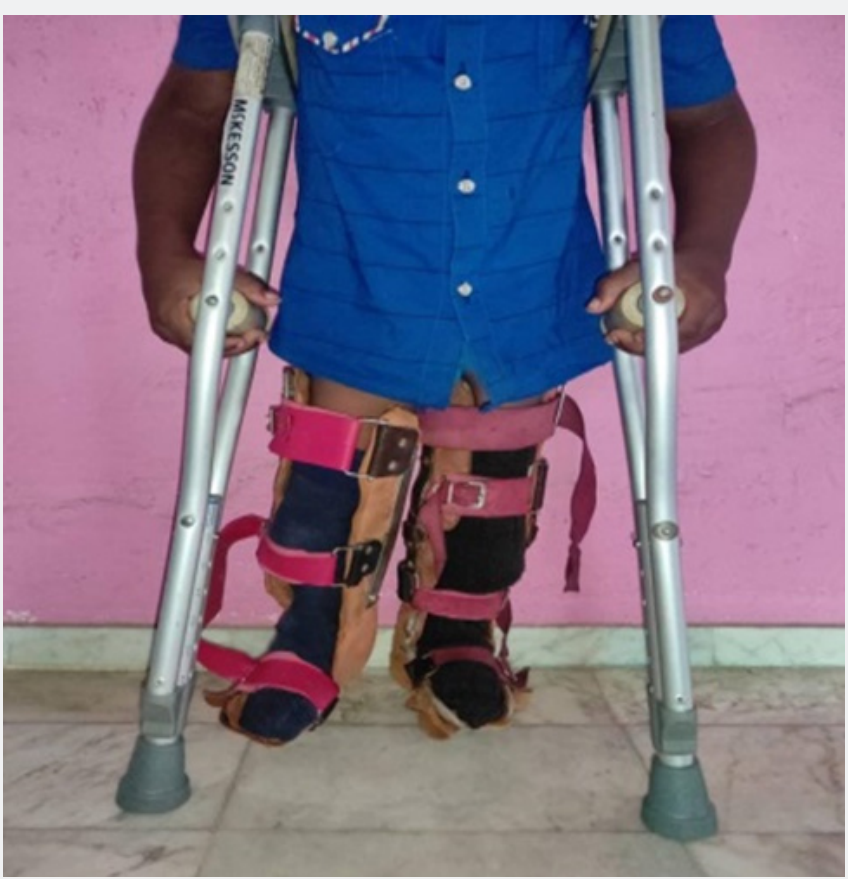

Figure 4: Clinical picture taken at 20 weeks after surgery. The boy can mobilize with the use of crutches. However, he still has some residual bilateral cavovarus feet deformities.

\section{Discussion}

Gollop-Wolfgang Complex (GWC) is a rare congenital limb anomaly characterized by tibial aplasia, ipsilateral bifurcation of the thighbone and ectrodactyly [1-3]. Very often, the anomalies of limbs, heart, digestive and urinary tracts and the lumbosacral vertebrae are also associated $[3,14]$. In our case, the 6-year-old 
boy had a bifurcated right femur, bilateral tibia hemimelia and a hypoplastic toe consistent with a Gollop Wolfgang complex. However, there were no other malformations recorded on examination. Gollop Wolfgang complex is listed as a "rare disease" by the United States Office of Rare Diseases (ORD) of the National Institute of Health (NIH) [1], and there are only few cases reported in Africa $[9,11,12]$.

The etiology of GWC is most likely an error in the complex genetic control of limb development but the exact cause is still unclear [3]. A report describing a patient with multiple congenital anomalies (including distal femoral bifurcation and bilateral fibular agenesis) resulting from a deletion of proximal part of chromosome 8q(8q11-q13), was suggestive of the role of a gene on chromosome $8 q$ in lower limb development [15]. It has also been found in parents who are consanguineous [13]. Fetal GWC has been reported in three siblings, two females and a male, born to a mother using carbamazepine. The possible explanations may be a teratogenic effect of carbamazepine [15]. In our case, parents were not consanguineous, and there was no history of use of carbamazepine before, during or after the pregnancy.

Surgical correction of GWC is still very difficult and does not have a predefined protocol or procedure [12-14]. The best treatment option for patients with GWC is early knee disarticulation and resection of the protruded bifurcated femur followed by fitting of a modern prosthesis [9-11]. Those with complete tibial hemimelia like in this case have an uncertain longterm outcome and require intensive post-operative rehabilitation. Such cases may subsequently need more reconstructive options like fibular transfer (Brown's procedure) and callus distraction lengthening [9], which are not practicable in our context but possible in developed countries $[1,13]$. It is recommended to do an amputation in case the short/long term outcome after limb salvage treatment is not satisfactory, especially when there is absence of proximal tibial anlage $[3,12,14]$.

This is the first case of GWC treated without amputation in a limited resource setting. A close follow-up of this case is paramount given the fact that the boy still has some residual feet cavus deformity and would have his KAFO subsequently and regularly modified to accommodate growth. Although the shortterm outcome in our case is satisfactory, the parents have been counseled on the possibility of an amputation and prosthetic replacement if the long-term outcome is not satisfactory.

\section{Conclusion}

Limb salvage surgery of GWC is a difficult treatment option in limited resource settings. It could be a good alternative to amputation especially in the absence of parental consent to amputation. Although the initial result obtained with limb salvage is comparable to amputation, further research in this rare anomaly are needed to evaluate the long term outcome of this treatment option.

\section{Clinical Message}

Gollop-Wolfgang Complex is a rare disease and only few cases have been reported in Africa. The treatment of this pathology is still very unclear though limb disarticulation and prosthetic replacement is advised. Limb salvage surgeries have also been practiced in cases of absence of parental consent with initial results comparable to amputation. Studies on long term outcome of salvage surgeries for GWC should be carried out.

\section{Consent}

The parents gave their consent for the study.

\section{Conflict of Interest}

The authors declare that this manuscript was approved by all authors in its current form, and they have no competing interests.

\section{Authors' Contributions}

Doctors Nana C Theophile and Arung J Etaya performed the surgery supervised by Doctor Palle J Ngunde. Doctors Batchom, Bombah, Ebai supervised physiotherapy sessions. All authors read and approved the manuscript.

\section{Source of Funding}

None.

\section{Acknowledgement}

We thank Dr Annereke Nyenti, the Director of the Limbe Regional Hospital who waived off most of the patient's surgery and physiotherapy bills.

\section{References}

1. Wada A, Nakamura T, Fujii T, Urano N, Yanagida H, et al. (2013) Limb salvage treatment for Gollop Wolfgang complex (femoral bifurcation, complete tibial hemimelia, and hand ectrodactyly). J Pediatr Orthop Part B 22(5): 457-463.

2. Dhanakodi N, Tripathy SK (2014) Gollop-Wolfgang syndrome. Indian J Med Res 139(6): 963-964.

3. Bos CF, Taminiau AH (2007) A 5-year follow-up study after knee disarticulation in two cases of Gollop-Wolfgang complex. J Pediatr OrthopB 16: 409-413.

4. Gollop TR, Lucchesi E, Martins RM, Nione AS (1980) Familial occurrence of bifid femur and monodactylous ectrodactyly. Am J Med Genet 7(3): 319-322.

5. Wolfgang GL (1984) Complex congenital anomalies of the lower extremities: femoral bifurcation, tibial hemimelia, and diastasis of the ankle. Case report and review of the literature. J Bone Joint Surg Am 66(3): 453-458.

6. Lurie IW, Ilyina HG (1986) Gollop-Wolfgang complex in a 3-month-old girl. Am J Med Genet Suppl 2: 191-194.

7. Guven MA, Batukan C, Ceylaner S, Ceylaner G, Uzel M (2006) A case of fetal anticonvulsant syndrome with severe bilateral upper limb defect. J Matern Fetal Neonatal Med 19(2): 115-117. 
8. Muzaffar N (2013) Tibial agenesis and Gollop-Wolfgang complex in three siblings born to an epileptic woman treated with carbamazepine: teratogenicity? Genetics 2: 118 .

9. EA Orimolade, IC Ikem, LM Oginni, AO Odunsi (2011) Femoral bifurcation with ipsilateral tibia hemimelia: Early outcome of ablation and prosthetic fitting; Nigerian Journal of Clinical Practice 14(4): 492 494.

10. Qureshi IA, Gudepu RK, Chava R, Sravya Emmani, Syed Husain Asghar et al. (2015) Case Report: Gollop-Wolfgang Complex in a 5-month-old baby. F1000Res 3: 315.

11. Ondari J, Kinyanjui J, Miano P, Sang E, Oburu E, et al. (2018) Femoral bifurcation and bilateral tibial hemimelia: case report. Pan Afr Med J 30: 99.
12. Seid Mohammed, Richard O E (2020) Gollop-wolfgang complex in an 18 years old female Ethiop Med J 58(4)

13. Alice Nlandu, Pierre-Louis docquier (2013) Gollop-Wolfgang Complex: an alternative to amputation. Acta Orthop Belg 79(2): 239-242.

14. Erickson RP (2005) Agenesis of tibia with bifid femur, congenital heart disease, and cleft lip with cleft palate or tracheoesophageal fistula: possible variants of Gollop-Wolfgang complex. Am J Med Genet A 134(3): 315-317.

15. Asamoah A, Nwankwo M, Kumar SP, Ezhuthachan SG, Van Dyke DL (2004) Proximal chromosome 8q deletion in a boy with femoral bifurcation and other multiple congenital anomalies. Am J Med Genet 127A: 65-68.

\section{Your next submission with Juniper Publishers will reach you the below assets}

- Quality Editorial service

- Swift Peer Review

- Reprints availability

- E-prints Service

- Manuscript Podcast for convenient understanding

- Global attainment for your research

- Manuscript accessibility in different formats ( Pdf, E-pub, Full Text, Audio)

- Unceasing customer service

Track the below URL for one-step submission https://juniperpublishers.com/online-submission.php 